\title{
Breeding of Moricandia arvensis Monosomic Chromosome Addition Lines (2n=19) of Alloplasmic (M. arvensis) Raphanus sativus
}

\author{
Sang Woo Bang*1), Yukio Kaneko(), Yasuo Matsuzawa ${ }^{1)}$ and Keuk Soo Bang ${ }^{2)}$ \\ 1) Laboratory of Plant Breeding, Faculty of Agriculture, Utsunomiya University, 350 Minemachi, Utsunomiya, Tochigi 321-8505, Japan \\ 2) Laboratory of Plant tissue culture \& Breeding, Dept. of Biotechnology, Iksan National College, 194-5, Ma-Dong, Iksan-City, Chonbuk \\ 570-752, Korea
}

By backcrossing to Raphanus sativus cv. 'Pink ball', 55 $\mathrm{BC}_{2}$ plants were obtained from two sesquidiploidal $\mathrm{BC}_{1}$ plants (MaRR, 2n=32) between Moricandia arvensis $(M a M a, 2 n=28)$ and $R$. sativus $(\mathrm{R}, 2 \mathrm{n}=18)$. Their somatic chromosome numbers ranged from $2 n=18$ to $2 n$ $=23$, except for one hyperploid plant with $2 n=44$. In the $\mathrm{BC}_{3}$ generation, 64 plants $(2 \mathrm{n}=19)$ were generated from $16 \mathrm{BC}_{2}$ plants with $2 \mathrm{n}=19 \sim 23$. Each plant with $2 \mathrm{n}=19$ exhibited both morphological and physiological characteristics diagnostic for the presence of an added chromosome of $M$. arvensis genome, and showed predominantly the chromosome pairing type of $9 \mathrm{II}+1 \mathrm{I}$ at metaphase I of PMCs. They were classified into twelve (a l) types of monosomic chromosome addition lines (MALs) of alloplasmic (M. arvensis) R. sativus carrying $M$. arvensis cytoplasm by their morphological, physiological and cytogenetical characteristics. The mean of seed setting in the twelve types of MALs ranged from $\mathbf{2 . 8 8}$ grains (f-type) to $\mathbf{0 . 5 1}$ grains (j-type) per pollinated flower when they were backcrossed to $R$. sativus cv. 'Pink ball'. The transmission rates to the next generation through female gametes ranged from $32.5 \%$ (f- and j-types) to $\mathbf{5 . 5 \%}$ (h-type) when smaller seeds were selectively grown. The specific characteristics of each type of MALs were transmitted from the $\mathrm{BC}_{3}$ generation to the $\mathrm{BC}_{4}$ and $\mathrm{BC}_{5}$ ones without any modification. The MALs of the distinctive twelve types were also identified using RAPD markers in the $\mathrm{BC}_{5}$ generation. Pollen fertility of the twelve types of MALs ranged from $85.6 \%$ (c-type) to $3.4 \%$ (l-type), although four types (g-, h-, i- and jtypes) exhibited complete male sterility. Furthermore, alloplasmic (M. arvensis) $R$. sativus plants $(2 n=18)$ which were derived from male fertile MALs showed complete male sterility. The twelve types of MALs produced in this study should be useful materials to determine the localization of genes for agronomic traits on the individual chromosome of $M$. arvensis and the alloplasmic (M. arvensis) $R$. sativus should also be a useful material for the development of a new cytoplasmic male sterility system in $R$. sativus.

Communicated by H. Namai

Received November 8, 2001. Accepted March 11, 2002.

*Corresponding author (e-mail: bang@cc.utsunomiya-u.ac.jp)
Key Words: Moricandia arvensis, Raphanus sativus, monosomic chromosome addition lines (MALs), alloplasmic (M. arvensis) $R$. sativus, male sterility.

\section{Introduction}

Moricandia arvensis (L.) DC. $(2 \mathrm{n}=28, \mathrm{MaMa})$ is one of the $\mathrm{C}_{3}-\mathrm{C}_{4}$ intermediate species of Brassicaceae that are characterized by a high concentration of organelles in the bundle-sheath cells and low $\mathrm{CO}_{2}$ compensation concentrations. In Brassicaceae, other $\mathrm{C}_{3}-\mathrm{C}_{4}$ intermediate species were found within species of the genera Moricandia, Diplotaxis and Brassica (Apel et al. 1996, 1997). Apel et al. (1984) reported the photosynthetic properties of the $\mathrm{F}_{1}$ and $\mathrm{BC}_{1}$ plants between $B$. alboglabra $\left(\mathrm{C}_{3}\right.$ species $)$ and $M$. arvensis, and suggested that the $\mathrm{C}_{3}-\mathrm{C}_{4}$ intermediate trait, especially low photo-respiration activity, might be valuable for the breeding of Brassica crops. In order to analyze the genetic characteristics of the $\mathrm{C}_{3}-\mathrm{C}_{4}$ intermediate trait and to introduce it into the cultivated species, a number of intergeneric hybrids between $M$. arvensis and some $\mathrm{C}_{3}$ species in Brassicaceae have been obtained through the application of the conventional pollinating method, embryo rescue technique and protoplast fusion (Toriyama et al. 1987, Takahata 1990, Takahata and Takeda 1990, Takahata et al. 1993, Kirti et al. 1992, Razmjoo et al. 1996, Bang et al. 1996). However, very little is known about the evolution and genetic system of the $\mathrm{C}_{3}-\mathrm{C}_{4}$ intermediate species in Brassicaceae.

Since the monosomic chromosome addition lines (MALs) of Raphanus sativus-B. oleracea and B. rapa-B. oleracea were produced by Kaneko et al. (1987) and Quiros et al. (1987) respectively, several of MAL series have been successfully bred through interspecific and intergeneric hybridization (Quiros et al. 1988, Jahier et al. 1989, Chen et al. 1992, Srinivasan et al. 1998, Kaneko et al. 2001). These MALs were also examined for the analysis of agronomic traits and gene(s) that were assumed to be located on the added chromosomes from the B and $\mathrm{C}$ genomes of Brassica species (Zhu et al. 1993, Chevre et al. 1996, 1997, Kaneko et al. 1996, 2000, Chen et al. 1997). The advantages of using MALs include the possibility of assigning species-specific gene(s) and/or characteristics to particular chromosomes, 
and the potential to transfer desirable agronomic traits between species (Namai 1987, McGrath and Quiros 1990, Matsuzawa et al. 1996).

In our previous paper, it was reported that the intergeneric $\mathrm{F}_{1}$ hybrids between $M$. arvensis and $R$. sativus $\left(\mathrm{C}_{3}\right.$ species) were produced through the application of the embryo rescue technique when $M$. arvensis was used as a pistillate parent, and then $\mathrm{BC}_{2}$ seeds were obtained by successive backcrosses to R. sativus cv. 'Pink ball' (Bang et al. 1996). In this study, twelve types of MALs of alloplasmic ( $M$. arvensis) $R$. sativus will be described with reference to their morphological, physiological and cytogenetical characteristics in addition to RAPD markers.

\section{Materials and Methods}

Plant materials and production of monosomic chromosome addition lines (MALs)

M. arvensis (strain 4) is an accession of Cruciferae genetic stocks from the Laboratory of Plant Breeding, Tohoku University, Japan. R. sativus cv. 'Pink ball' for the recurrent parent is an accession from the Laboratory of Plant Breeding, Utsunomiya University, Japan. $\mathrm{BC}_{2}$ seeds used in this study were obtained from two sesquidiploidal $\mathrm{BC}_{1}$ plants (MaRR, $2 \mathrm{n}=32$ ) between $M$. arvensis (MaMa, $2 \mathrm{n}=28)$ and $R$. sativus cv. 'Pink ball' ( $\mathrm{RR}, 2 \mathrm{n}=18$ ) by backcrossing to $R$. sativus cv. 'Pink ball' (Bang et al. 1996). Out of them, the fully mature 83 seeds were sown in small pots and then 55 $\mathrm{BC}_{2}$ plants were grown in a greenhouse after being transplanted to ceramic pots $18 \mathrm{~cm}$ in diameter. The $\mathrm{BC}_{2}$ plants with $2 \mathrm{n}=19 \sim 23$ were successively backcrossed to $R$. sativus cv. 'Pink ball' to maintain and newly generate the MAL with $2 n=19$ in the $\mathrm{BC}_{3}$ generation. All the plants with $2 \mathrm{n}=19$ were firstly classified into twelve types of MALs based on the morphological, physiological and cytogenetical characteristics in the $\mathrm{BC}_{3}$ generation, and were successfully maintained as distinctive MALs to the $\mathrm{BC}_{5}$ generation through successive backcrosses to $R$. sativus cv. 'Pink ball'

\footnotetext{
Morphological, physiological and cytogenetical characteristics of twelve types of MALs

Twelve types of MALs were identified based on the morphological and physiological characteristics of their leaves, roots and flowers and the cytogenetical features in the $\mathrm{BC}_{3}$ generation. Chlorophyll content was determined using a chlorophyll meter (SPAD-502, Minolta, Japan) and several leaf characters were measured when the leaves were fully extended. Root diameter was measured on the more enlarged part during the period of seed setting. The measurements of petal length, petal width and ovary length were made using ten flowers in full bloom. The number of ovules was counted using 10 ovaries under a fluorescence microscope after staining with $0.1 \%$ aniline blue. Bolting was recorded by observing the mean days from sowing to bolting when flower buds protruded from the rosette. Plant height was measured when the individual plants were in full bloom.
}

Somatic chromosomes were observed using the Feulgen stain squash method followed by $1 \%$ acetocarmine staining. At least 20 clear metaphases I (MI) in pollen mother cells (PMCs) per MAL plant were observed using the $1 \%$ acetic orcein smear method for the determination of meiotic chromosome pairing. Pollen tetrad was observed in at least 500 sporads after staining with $1 \%$ acetic orcein. Pollen fertility was ascertained by observing 1000 pollen grains after staining with $1 \%$ acetocarmine. Seed setting was determined by counting the number of mature seeds per pollinated flower when the MAL plants were backcrossed to R. sativus. Transmission rate of the added chromosome in each type of MALs through female gametes was calculated by observing about 30 plants per each type in the $\mathrm{BC}_{4}$ and $\mathrm{BC}_{5}$ generations that were grown from the selected smaller seeds according to the method of Kaneko et al. (1991).

\section{RAPD analysis}

RAPD markers were employed to confirm the validity of the twelve types of MALs in the $\mathrm{BC}_{5}$ generation according to the method of Kaneko et al. (2001). Total DNA was extracted from young leaves of MAL plants using the Extraction Kit (Nucleon Phyto Pure, Scotlab Bioscience, Buckingham, UK). Random 10-mers primers used in this study were selected from 40 primers (kit OPA, OPE, OPR and OPT, Operon Tech. Co., Alameda, CA, USA). For DNA amplification, a thermocycler (Program-tempucontrol system PC-700, ASTEC Co., Fukuoka, Japan) was used; the DNA templates that were resolved by Analysis Kit (ReadyTo-Go, Pharmacia, NJ., USA) in $0.5 \mathrm{ml}$ tubes were amplified according to the schedule for DNA amplification developed by Kaneko et al. (2000). The samples were run in 5\% polyacrylamide for $50 \mathrm{~min}$ at $40 \mathrm{~mA}$ to separate the amplified products, which were visualized by ethidium bromide $(0.5$ $\mu \mathrm{g} / \mathrm{ml})$ staining. These procedures were repeated twice. The reliable bands that were not observed in $R$. sativus cv. 'Pink ball', but obtained consistently in $M$. arvensis, were assigned to RAPD bands specific to MALs.

\section{Results}

Production of twelve types of MALs and their morphological, physiological and cytogenetical characteristics

The somatic chromosome number of $55 \mathrm{BC}_{2}$ plants ranged from $2 n=18$ to $2 n=23$, except for one hyperploid plant with $2 n=44$ (Table 1 ). The plants with $2 n=20$ were obtained in the highest frequency $(25.5 \%)$, followed by $2 n=18$ $(21.8 \%), 2 \mathrm{n}=19(20.0 \%)$, and both $2 \mathrm{n}=21$ and $2 \mathrm{n}=22(14.6$ $\%)$. When $16 \mathrm{BC}_{2}$ plants with $2 \mathrm{n}=19 \sim 23$ were successively backcrossed to $R$. sativus, $214 \mathrm{BC}_{3}$ plants were obtained. Their somatic chromosome number ranged from $2 n=18$ to $2 \mathrm{n}=21$, except for 2 plants with $2 \mathrm{n}=27$ (Table 1 ). Most of them were $2 n=18$ (138 plants), followed by $2 n=19$ (64), $2 n$ $=20(8)$ and $2 n=21$ (2). Sixty-four plants with $2 n=19$ were consecutively and newly generated from 16 plants of $\mathrm{BC}_{2}$, consisting of 2 primary MAL plants with $2 \mathrm{n}=19,7$ plants 
Table 1. Distribution of somatic chromosome numbers in $\mathrm{BC}_{2}$ and $\mathrm{BC}_{3}$ plants derived from two sesquidiploid $\mathrm{BC}_{1}$ plants $(2 \mathrm{n}=32)$ after successive backcrosses to $R$. sativus cv. 'Pink ball'

\begin{tabular}{rcccccccc}
\hline \hline \multirow{2}{*}{ Line } & No. of plants & \multicolumn{6}{c}{ Somatic chromosome number (2n) } \\
\cline { 3 - 9 } & Observed & 18 & 19 & 20 & 21 & 22 & 23 & $23<$ \\
\hline $\mathrm{BC}_{2}$ & 55 & 12 & 11 & 14 & 8 & 8 & 1 & 1 \\
& $(\%)$ & 21.8 & 20.0 & 25.5 & 14.6 & 14.6 & 1.8 & 1.8 \\
$\mathrm{BC}_{3}{ }^{1)}$ & 214 & 138 & 64 & 8 & 2 & & 2 \\
& $(\%)$ & 64.5 & 29.9 & 3.7 & 0.9 & & 0.9 \\
\hline
\end{tabular}

1) $\mathrm{BC}_{3}$ plants were obtained from $16 \mathrm{BC}_{2}$ plants with $2 \mathrm{n}=19 \sim 23$ by backcrossing to $R$. sativus cv. 'Pink ball'.

with $2 \mathrm{n}=20,3$ plants with $2 \mathrm{n}=21,3$ plants with $2 \mathrm{n}=22$ and one plant with $2 \mathrm{n}=23$. Another 26 plants of $\mathrm{BC}_{2}$ with $2 \mathrm{n}=$ 19 22 showed a lower seed setting or complete sterility, resulting in the failure to transmit the added chromosome(s) to the $\mathrm{BC}_{3}$ generation.

Compared with $R$. sativus cv. 'Pink ball' and alloplasmic (M. arvensis) $R$. sativus $(2 \mathrm{n}=18)$, all the plants with $2 \mathrm{n}$ $=19$ exhibited distinctive and diagnostic features based on morphological, physiological and cytogenetical characteristics, resulting from the presence of an added chromosome of $M$. arvensis genome $(n=14)$. Based on their specific characteristics in the $\mathrm{BC}_{3}$ generation, 64 plants $(2 \mathrm{n}=19)$ were classified into twelve types of MALs of alloplasmic $(M$. arvensis) $R$. sativus, and tentatively referred to as the atype to 1-type (Table 2). Morphological, physiological and cytogenetical characteristics were also observed for each type of MALs in the $\mathrm{BC}_{3}, \mathrm{BC}_{4}$ and $\mathrm{BC}_{5}$ generations (Table 3 ).

Significant differences between $R$. sativus cv. 'Pink ball' and $M$. arvensis were recognized in the morphological and physiological characteristics of the leaves, roots and flowers. The leaves of $R$. sativus showed numerous lobes, the petals and roots were tinged with pink and the roots were enlarged (Fig. 1A). On the other hand, M. arvensis exhibited spatulate leaves, the sepals and petals were tinged with purple, the roots were not enlarged and the plants displayed an early bolting character (Fig. 1B). The a-type plants had twisted leaves with a large number of lobes, and the roots and petal organs were pale-pink. The b-type plants showed crenate lobes, and a conspicuous purple pigmentation on the surface of the roots and both sepal and petal organs. The ctype plants showed whitish roots and wide intervals between lobes, and exhibited the highest pollen fertility (85.6\%). On the other hand, the alloplasmic (M. arvensis) R. sativus $(2 \mathrm{n}=18)$ and four types of MALs (g-, h-, i- and j-types) showed male sterility but their flowers had well-developed anthers and nectaries. In the d-type plants, the leaves were lighter green and thinner, and the flowers were smaller and purplish-pink with a low pollen fertility (Fig. 1C). The etype plants, however, were characterized by green leaves with denticulate lobes and larger petal and ovary organs than those of the other types. The f-type plants showed an erect type and had sleek leaves with wider intervals between the lobes, and exhibited the highest seed setting ( 2.88 grains) and the highest transmission rate of $32.5 \%$ when smaller seeds were selectively grown. The g-type plants had the darkest green leaves and small roots. The h-type plants exhibited the longest leaves with a small number of lobes, and showed the lowest transmission rate $(5.5 \%)$. The i-type plants had short and narrow leaves with many lobes compared with those of the c-, f- and h-types, and the petals were purplish-pink. In the j-type plants, the leaves were light green and short with a small number of lobes, and the plants exhibited the highest transmission rate of $32.5 \%$. The k-type plants had stiff and wrinkled leaves with a dentate leaf margin (Fig. 1D), and showed a lower pollen fertility (12.0\%). The l-type plants closely resembled the alloplasmic $(M$. arvensis) $R$. sativus $(2 \mathrm{n}=18)$ plants except for the slightly dark green leaves, the long and wide petals and some fertile pollen $(3.4 \%)$.

The plants of all types of MALs exhibited predominantly the chromosome pairing type of 9II + 1I at MI of PMCs (Fig. 2, Table 3) and had pollen tetrads that appeared normal as in the case of $R$. sativus cv. 'Pink ball'. However, their pollen fertility showed a significant difference, as mentioned above. No significant correlation was recognized between pollen fertility and seed setting although seed setting in each type of MALs ranged from 2.88 grains (f-type) to 0.51 grains (j-type). Accordingly, both pollen fertility and seed setting could be utilized as a potential genetic marker to identify each type of MALs.

\section{RAPD analysis}

RAPD markers in the twelve types of MALs are shown in Table 4. The number of markers for each type of MALs

Table 2. Classification of twelve types of MAL $(\mathrm{a} \sim 1,2 \mathrm{n}=19)$ derived from $\mathrm{BC}_{2}$ plants $(2 \mathrm{n}=19 \sim 23)$ by backcrossing to $R$. sativus cv. 'Pink ball'

\begin{tabular}{|c|c|c|c|c|c|c|c|c|c|c|c|c|c|}
\hline \multirow{2}{*}{$\begin{array}{c}\text { No. of plants } \\
\text { observed }\end{array}$} & \multicolumn{13}{|c|}{ Plant type } \\
\hline & $\mathrm{a}$ & $b$ & $\mathrm{c}$ & $\mathrm{d}$ & e & $\mathrm{f}$ & $\mathrm{g}$ & $\mathrm{h}$ & $\mathrm{i}$ & $\mathrm{j}$ & $\mathrm{k}$ & 1 & $\mathrm{x}^{1)}$ \\
\hline 64 & 8 & 4 & 3 & 2 & 1 & 2 & 3 & 2 & 5 & 5 & 8 & 1 & 20 \\
\hline
\end{tabular}

1) Unidentified type of MALs. 

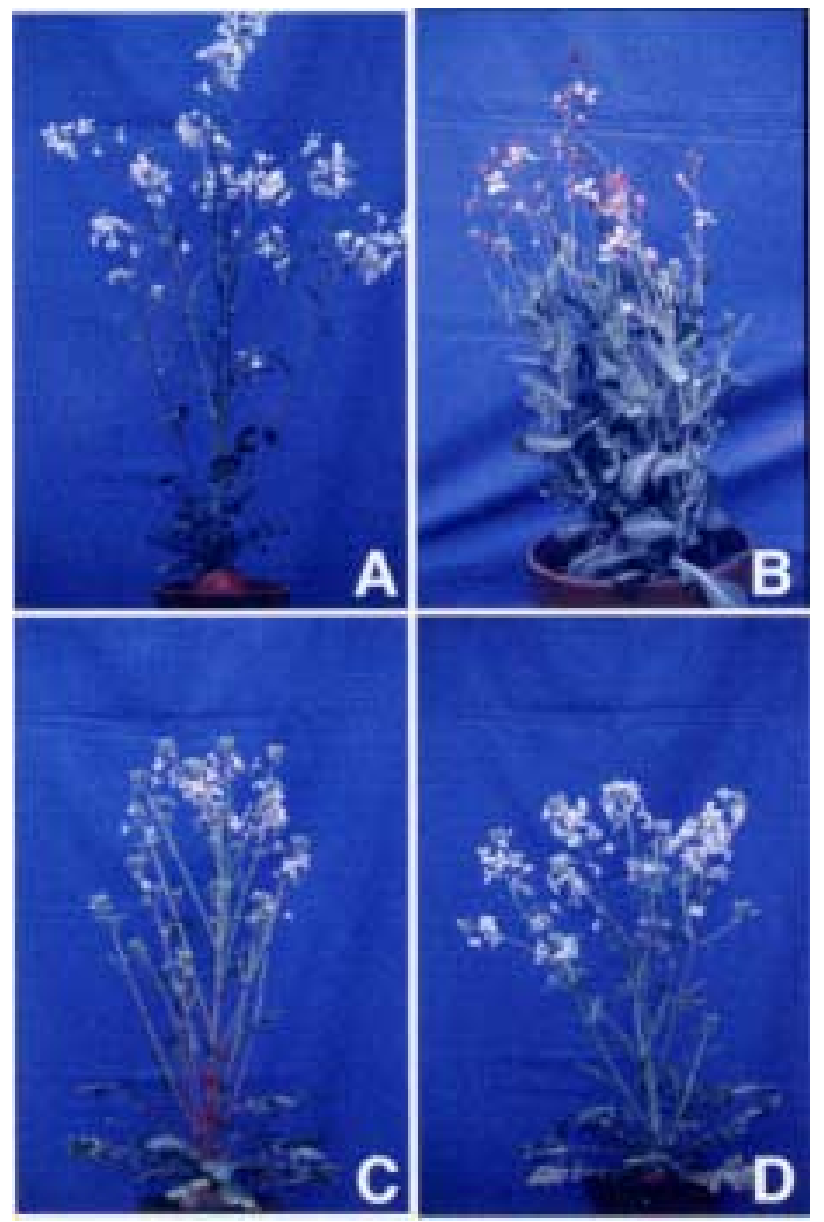

Fig. 1. Comparison of morphological characteristics of parental species and MAL plants. A: Raphanus sativus $(2 \mathrm{n}=18)$, B: Moricandia arvensis $(2 \mathrm{n}=28)$, C: d-type of MAL $(2 \mathrm{n}=19)$ and D: k-type of MAL $(2 n=19)$.

ranged from 9 (d-type) to 24 (i-type). Among these bands, RAPD markers specific to each type alone ranged from one for the a-type and b-type to five for the i-type. No marker was observed alone for the d-type, e-type, g-type and h-type of MALs. The g-type and h-type of MALs closely resembled each other in the pattern of bands in spite of their distinctive plant morphology.

\section{Discussion}

For the successful classification of MALs, it is essential to use specific markers. The morphological characteristics could be suitable markers for classifying the MALs especially when the two species concerned showed significant differences in their morphological characteristics. In this study, $R$. sativus cv. 'Pink ball' and $M$. arvensis showed significant differences in morphological characteristics, as mentioned above. We were able to classify twelve types of MALs of alloplasmic (M. arvensis) R. sativus $(2 \mathrm{n}=19, \mathrm{RR}+1 \mathrm{ma})$ based on their morphological, physiological and cytogenetical characteristics, and confirmed that the specific characteristics of each type of MALs were transmitted through female



Fig. 2. Chromosome pairing type of $9 \mathrm{II}+1 \mathrm{I}$ at metaphase I of pollen mother cell in a monosomic addition line (MAL).

gametes from $\mathrm{BC}_{3}$ to $\mathrm{BC}_{4}$ and $\mathrm{BC}_{5}$ generations without any modification (Table 3). The twelve types of MALs showed adequate seed setting $(0.51 \sim 2.88$ grains $)$ and transmission rates $(5.5 \% \sim 32.5 \%)$ to permit their successful maintenance when they were backcrossed to $R$. sativus. The MALs of the distinctive twelve types were reconfirmed using RAPD markers in the $\mathrm{BC}_{5}$ generation (Table 4). These results led to the conclusion that the twelve types of MALs produced in this study were true MALs of alloplasmic (M. arvensis) $R$. sativus and the morphological, physiological and cytogenetical characteristics in addition to RAPD-specific markers were essential to classify each type of MALs.

We were unable to obtain fourteen types of MALs corresponding to the $M$. arvensis genome $(\mathrm{n}=14, \mathrm{Ma})$. In other MALs in Brassicaceae, complete series of MALs had not been developed (Kaneko et al. 1987, 2001, Quiros et al. 1987, 1988, Jahier et al. 1989, Chen et al. 1992, Srinivasan et al. 1998). To produce all the MALs, cross incompatibility within interspecific and intergeneric hybridization and successive backcrosses to background species has to be overcome. In a previous study (Bang et al. 1996), we were able to obtain the $\mathrm{BC}_{2}$ seeds by overcoming the barrier(s) existing in the intergeneric hybridization between $M$. arvensis and $R$. sativus and in the backcrossing of $\mathrm{F}_{1}$ hybrids to $R$. sativus through the application of the embryo rescue technique followed by chromosome doubling for the $\mathrm{F}_{1}$ hybrids. In this study, 26 plants out of $42 \mathrm{BC}_{2}$ plants with one to five alien chromosomes $(2 \mathrm{n}=19 \sim 23)$ could not generate plants with added chromosomes in $\mathrm{BC}_{3}$. The missing two types of MALs may be included in these plants. Therefore, it was suggested that a genetic system controlling the cross incompatibility in intergeneric hybridization between $M$. arvensis and $R$. sativus occurred on a few chromosomes of the $M$. arvensis genome, most likely on the missing two chromosomes.

Out of twelve types of MALs (a-type $\sim$ 1-type) carrying the $M$. arvensis cytoplasm, four types (g-, h-, i- and j-types) showed a complete male sterility and the other MALs showed a pollen fertility ranging from 3.4\% (l-type) to 85.6 $\%$ (c-type) whereas reverted alloplasmic (M. arvensis) $R$. sativus $(2 \mathrm{n}=18)$ predominantly exhibited complete male sterility (Table 3). Therefore, it appears that the restoration 
Table 3. Morphological, physiological and cytogenetical characteristics of twelve types (a l) of MALs in $\mathrm{BC}_{3}$ to $\mathrm{BC}_{5}$ generations, $R$. sativus (R), alloplasmic R. sativus and M. arvensis (Ma)

\begin{tabular}{|c|c|c|c|c|c|c|c|c|c|c|c|c|c|c|c|}
\hline \multirow[b]{2}{*}{ Character } & \multicolumn{15}{|c|}{ Twelve types of MALs } \\
\hline & a & $\mathrm{b}$ & c & $\mathrm{d}$ & $\mathrm{e}$ & f & $\mathrm{g}$ & $\mathrm{h}$ & $\mathrm{i}$ & $\mathrm{j}$ & $\mathrm{k}$ & 1 & $\mathrm{R}$ & $\mathrm{aR}^{1)}$ & $\mathrm{Ma}$ \\
\hline No. of plants observed & 18 & 14 & 10 & 16 & 7 & 21 & 8 & 5 & 10 & 24 & 17 & 13 & 5 & 5 & 5 \\
\hline \multicolumn{16}{|l|}{ Leaf } \\
\hline Chlorophyll content $\left.{ }^{2}\right)$ & $32.2^{\mathrm{bc} 3)}$ & $31.2^{\mathrm{bc}}$ & $34.7^{\mathrm{bcd}}$ & $19.9^{\mathrm{a}}$ & $34.7^{\text {bcd }}$ & $28.8^{b}$ & $42.5^{\mathrm{d}}$ & $32.4^{\mathrm{bc}}$ & $32.4^{\mathrm{bc}}$ & $28.8^{b}$ & $35.8^{\mathrm{bcd}}$ & $38.8^{\mathrm{cd}}$ & $54.9^{e}$ & $31.5^{\mathrm{bc}}$ & $56.5^{\mathrm{e}}$ \\
\hline Length (cm) & $31.4^{\text {def }}$ & $30.9^{\text {cdef }}$ & $29.7^{\text {bcdef }}$ & $32.3^{3 \mathrm{ef}}$ & $29.7^{\text {bcdef }}$ & $26.8^{b}$ & $27.0^{\mathrm{b}}$ & $32.5^{\mathrm{f}}$ & $28.5^{\mathrm{bcd}}$ & $23.8^{\mathrm{a}}$ & $30.2^{\text {cdef }}$ & $30.0^{\text {cdef }}$ & $27.9^{b c}$ & $29.3^{\text {bcde }}$ & -4) \\
\hline Width (cm) & $10.9^{d}$ & $10.7^{d}$ & $10.8^{\mathrm{d}}$ & $10.1^{\mathrm{cd}}$ & $10.8^{\mathrm{d}}$ & $9.2^{\mathrm{bc}}$ & $8.3^{b}$ & $8.3^{b}$ & $7.0^{\mathrm{a}}$ & $10.7^{\mathrm{d}}$ & $11.2^{\mathrm{d}}$ & $10.8^{\mathrm{d}}$ & $10.5^{\mathrm{d}}$ & $10.0^{\mathrm{cd}}$ & - \\
\hline Thickness (mm) & $0.33^{\text {cde }}$ & $0.38^{\mathrm{f}}$ & $0.30^{\mathrm{abc}}$ & $0.26^{\mathrm{a}}$ & $0.37^{\mathrm{ef}}$ & $0.32^{\mathrm{bcd}}$ & $0.30^{\mathrm{abc}}$ & $0.32^{\mathrm{bcd}}$ & $0.27^{\mathrm{ab}}$ & $0.38^{\mathrm{f}}$ & $0.37^{\mathrm{ef}}$ & $0.35^{\text {def }}$ & $0.37 \mathrm{ef}$ & $0.33^{\text {cde }}$ & - \\
\hline No. of lobe & $12.5^{\mathrm{cd}}$ & $11.5^{\mathrm{bcd}}$ & $9.0^{\mathrm{b}}$ & $10.3^{\text {bcd }}$ & $13.0^{\mathrm{cd}}$ & $9.0^{\mathrm{b}}$ & $10.3^{b c d}$ & $10.0^{b c}$ & $13.5^{\mathrm{d}}$ & $10.8^{\mathrm{bcd}}$ & $12.8^{\mathrm{cd}}$ & $12.0^{\mathrm{bcd}}$ & $10.3^{b c d}$ & $11.0^{\mathrm{bcd}}$ & $0^{\mathrm{a}}$ \\
\hline \multicolumn{16}{|l|}{ Root } \\
\hline Diameter $(\mathrm{cm})$ & $4.1^{\mathrm{ab}}$ & $4.4^{\mathrm{abc}}$ & $4.3^{\mathrm{abc}}$ & $4.4^{\mathrm{abc}}$ & $4.9^{\mathrm{abc}}$ & $3.7^{\mathrm{a}}$ & $3.5^{\mathrm{a}}$ & $4.5^{\mathrm{abc}}$ & $5.6^{\mathrm{c}}$ & $4.7^{\mathrm{abc}}$ & $4.0^{\mathrm{a}}$ & $4.4^{\mathrm{abc}}$ & $7.5^{\mathrm{d}}$ & $5.5^{\mathrm{bc}}$ & - \\
\hline Color & pale-pink & purple & white & pink & pale-pink & pink & pale-pink & pink & pink & pink & pink & pink & pink & pink & pale-green \\
\hline \multicolumn{16}{|l|}{ Flower } \\
\hline Petal length (mm) & $20.7^{\text {def }}$ & $19.6^{\text {bcd }}$ & $20.3^{\text {cde }}$ & $15.1^{\mathrm{a}}$ & $21.6^{\mathrm{f}}$ & $21.3^{e f}$ & $19.9^{\mathrm{cd}}$ & $18.6^{\mathrm{b}}$ & $19.6^{b c}$ & $23.9 \mathrm{~g}$ & $21.4^{\mathrm{ef}}$ & $21.4^{\mathrm{ef}}$ & $21.7^{\mathrm{f}}$ & $18.5^{\mathrm{b}}$ & $23.7 \mathrm{~g}$ \\
\hline Petal width (mm) & $10.5^{\mathrm{g}}$ & $9.0^{\text {cde }}$ & $9.2^{\mathrm{de}}$ & $6.0^{\mathrm{a}}$ & $10.0^{\mathrm{fg}}$ & $10.8^{g}$ & $8.4^{\mathrm{bc}}$ & $6.5^{\mathrm{a}}$ & $8.6^{\text {bcd }}$ & $10.5^{\mathrm{g}}$ & $9.2^{\mathrm{de}}$ & $10.6^{g}$ & $9.5^{\mathrm{ef}}$ & $8.0^{\mathrm{b}}$ & $8.1^{\mathrm{b}}$ \\
\hline Petal color & pale-pink & purple & pale-pink & $\begin{array}{l}\text { purplish- } \\
\text { pink }\end{array}$ & pale-pink & pale-pink & pale-pink & pale-pink & $\begin{array}{l}\text { purplish- } \\
\text { pink }\end{array}$ & pale-pink & pale-pink & pale-pink & pink & pale-pink & purple \\
\hline Ovary length (mm) & $10.0^{\mathrm{f}}$ & $8.4^{\mathrm{c}}$ & $9.1^{\mathrm{d}}$ & $7.2^{\mathrm{a}}$ & $10.0^{\mathrm{f}}$ & $8.0^{\mathrm{b}}$ & $9.0^{\mathrm{d}}$ & $9.0^{\mathrm{d}}$ & $10.2^{\mathrm{f}}$ & $10.0^{\mathrm{f}}$ & $9.6^{\mathrm{e}}$ & $9.9^{\mathrm{ef}}$ & $11.0^{g}$ & $9.0^{\mathrm{d}}$ & $11.9^{\mathrm{h}}$ \\
\hline Ovule number & $4.6^{\mathrm{a}}$ & $4.2^{\mathrm{a}}$ & $3.9^{\mathrm{a}}$ & $4.5^{\mathrm{a}}$ & $5.8^{\mathrm{ab}}$ & $4.0^{\mathrm{a}}$ & $6.9^{b}$ & $6.9^{b}$ & $6.7^{\mathrm{b}}$ & $5.0^{\mathrm{ab}}$ & $5.8^{\mathrm{ab}}$ & $5.5^{\mathrm{ab}}$ & $4.9^{\mathrm{ab}}$ & $4.3^{\mathrm{a}}$ & $73.2^{c}$ \\
\hline Bolting (day) & $191.3^{b}$ & $193.5^{b}$ & $185.5^{\mathrm{b}}$ & $192.7^{\mathrm{b}}$ & $186.7^{\mathrm{b}}$ & $182.0^{\mathrm{b}}$ & $188.0^{\mathrm{b}}$ & $185.0^{\mathrm{b}}$ & $184.0^{\mathrm{b}}$ & $184.0^{\mathrm{b}}$ & $192.2^{b}$ & $184.5^{b}$ & $189.8^{b}$ & $180.3^{b}$ & $50.7^{\mathrm{a}}$ \\
\hline Plant height $(\mathrm{cm})$ & $46.7^{\mathrm{ab}}$ & $41.7^{\mathrm{ab}}$ & $51.3^{\mathrm{abc}}$ & $55.3^{\mathrm{abc}}$ & $43.0^{0 \mathrm{ab}}$ & $63.0^{c}$ & $47.0^{\mathrm{ab}}$ & $55.8^{\mathrm{abc}}$ & $47.0^{a \mathrm{ab}}$ & $52.5^{\mathrm{abc}}$ & $39.7^{\mathrm{a}}$ & $48.5^{\mathrm{abc}}$ & $57.2^{\mathrm{bc}}$ & $55.0^{\mathrm{abc}}$ & $49.8^{\mathrm{abc}}$ \\
\hline \multicolumn{16}{|l|}{ Chromosome pairing } \\
\hline at M I of PMCs & $9 I I+1 I$ & $9 I I+1 I$ & $9 I I+1 I$ & $9 \mathrm{II}+1 \mathrm{II}$ & $9 \mathrm{II}+1 \mathrm{II}$ & $9 I I+1 I$ & $9 \mathrm{II}+1 \mathrm{II}$ & $9 I I+1 I$ & $9 \mathrm{II}+1 \mathrm{II}$ & $9 I I+1 I$ & $9 \mathrm{II}+1 \mathrm{II}$ & $9 I I+1 I$ & 9II & 9II & 14II \\
\hline Pollen tetrad (\%) & $99.2^{2 \mathrm{~b}}$ & $98.1^{\mathrm{ab}}$ & $99.3^{\mathrm{ab}}$ & $98.7^{\mathrm{ab}}$ & $99.6^{\mathrm{b}}$ & $99.4^{\mathrm{ab}}$ & $99.8^{\mathrm{b}}$ & $99.7^{\mathrm{b}}$ & $99.5^{\mathrm{ab}}$ & $98.8^{\mathrm{ab}}$ & $97.6^{\mathrm{a}}$ & $99.6^{\mathrm{b}}$ & $100.0^{\mathrm{b}}$ & $99.7^{b}$ & $100.0^{\mathrm{b}}$ \\
\hline Pollen fertility (\%) & $60.2^{\mathrm{c}}$ & $53.9^{c}$ & $85.6^{\text {de }}$ & $22.9^{b}$ & $71.0^{\text {cd }}$ & $53.6^{\mathrm{c}}$ & $m s^{5) a}$ & $m s^{\mathrm{a}}$ & $\mathrm{ms}^{\mathrm{a}}$ & $m s^{\mathrm{a}}$ & $12.0^{\mathrm{ab}}$ & $3.4^{\mathrm{a}}$ & $97.9^{e}$ & $m s^{\mathrm{a}}$ & $98.0^{\mathrm{e}}$ \\
\hline Seed setting (grain) & $1.05^{\mathrm{ab}}$ & $2.32^{\text {bcde }}$ & $1.66^{\text {abcde }}$ & $1.03^{\mathrm{ab}}$ & $0.96^{\mathrm{ab}}$ & $2.88^{\mathrm{e}}$ & $2.59^{\text {cde }}$ & $1.2^{\mathrm{abc}}$ & $1.46^{\mathrm{abcd}}$ & $0.51^{\mathrm{a}}$ & $1.63^{\text {abcde }}$ & $2.08^{\text {bcde }}$ & $3.01^{\mathrm{de}}$ & $2.20^{\text {bcde }}$ & $8.10^{\mathrm{f}}$ \\
\hline Transmission rate $(\%)$ & $18.0^{\mathrm{abc}}$ & $17.0^{\mathrm{abc}}$ & $11.5^{\mathrm{ab}}$ & $24.0^{b c}$ & $10.0^{a \mathrm{ab}}$ & $32.5^{\mathrm{c}}$ & $8.0^{\mathrm{ab}}$ & $5.5^{\mathrm{a}}$ & $8.5^{\mathrm{ab}}$ & $32.5^{\mathrm{c}}$ & $15.0^{\mathrm{abc}}$ & $20.0^{\mathrm{abc}}$ & - & - & - \\
\hline
\end{tabular}

1) Alloplasmic $R$. sativus carrying M. arvensis cytoplasm $(2 \mathrm{n}=18)$.

2) Chlorophyll content was determined by the Soil Plant Air Determination system (SPAD) 502 value.

3) Numbers in the same column followed by different letters are significantly different at $p=0.05$ according to Duncan's multiple range test.

4) Not investigated.

5) Male sterility.

of pollen fertility for the alloplasmic (M. arvensis) R. sativus may be closely related to the presence of the added chromosome of M. arvensis. Alloplasmic B. juncea cv. 'Pusa Bold' carrying $M$. arvensis cytoplasm showed also the male sterility, whereas in alloplasmic B. juncea with one chromosome of M. arvensis, pollen fertility was $53 \%$ and the fertility restoring gene(s) were successfully introgressed into the alloplasmic $B$. juncea genome, resulting in the successful development of fertile plants with $93 \%$ pollen fertility (Prakash et al. 1998). The intergeneric hybrids of either diploid and amphidiploid species of Brassica (A, B, C, AC and AB genomes) or R. sativus (RR) with $M$. arvensis were obtained through the embryo rescue technique and cytogenetic observations of their hybrids suggested the existence of a partial homology between the $M$. arvensis genome and that of other Brassicaceae species (Takahata 1990, Takahata and Takeda 1990, Takahata et al. 1993, Bang et al. 1996). These results lead to the conclusion that $M$. arvensis cytoplasm has a higher potential for inducing the CMS line in Brassicaceae when the fertility restoring gene(s) are transferred from the $M$. arvensis genome to the crop species through meiotic recombination.

When each chromosome of the $M$. arvensis genome was introduced into the $R$. sativus genome, the characteristics under the control of the single chromosome were dominantly expressed in some organs of $R$. sativus. Accordingly, their characteristics were used as specific markers to identify each type of MALs. M. arvensis exhibited the distinctive bolting character (50.7 days) compared with $R$. sativus cv. 'Pink ball' (189.8 days). However, the bolting character of the twelve types of MALs did not show significant differences. These facts suggest that the genome of $R$. sativus $\mathrm{cv}$. 'Pink ball' may be epistatic against each chromosome of the $M$. arvensis genome at least for the bolting character. The late bolting character in Japanese radish was assumed to be controlled by multiple genes and expressed recessively against the early bolting one (Shinohara 1959, Kagawa 1971, Yuasa 1988). Kaneko et al. (1987, 2000) reported that the early bolting character expressed by the e-chromosome of the $B$. oleracea genome was dominant to the late bolting character of Japanese radish cv. 'Tokinashi', but recessive to the late bolting one under the g-chromosome of the same $B$. oleracea genome. In this study, the early bolting character of $M$. arvensis was recessively expressed against the bolting character of the $R$. sativus genome when each chromosome of the $M$. arvensis genome was introduced into the $R$. sativus 
Table 4. Distribution pattern of RAPD markers derived from M. arvensis in twelve types of MALs (bp)

\begin{tabular}{|c|c|c|c|c|c|c|c|c|c|c|c|c|}
\hline \multirow{2}{*}{ Primer } & \multicolumn{12}{|c|}{ Type of MALs } \\
\hline & $\mathrm{a}$ & $\mathrm{b}$ & $\mathrm{c}$ & $\mathrm{d}$ & $\mathrm{e}$ & $\mathrm{f}$ & $\mathrm{g}$ & $\mathrm{h}$ & $\mathrm{i}$ & $\mathrm{j}$ & $\mathrm{k}$ & 1 \\
\hline$\overline{\mathrm{OPA} 01}$ & 298,310 & $220,250,298,310$ & $270,298,310$ & & 298,310 & & 250,270 & 250,270 & 270,298 & 250 & 220,250 & 220,250 \\
\hline OPA07 & 344 & 240,344 & & & 344 & $220^{*}, 240$ & 240,344 & 240 & 344 & 344 & & \\
\hline OPA18 & & & & & & 320 & 320 & & $170^{*}, 320$ & 320 & $270^{*}, 320$ & 320 \\
\hline OPE05 & & 298 & 201,298 & 201,298 & 201,298 & & 201 & 201 & 201 & $320^{*}, 396 *$ & 298 & 201,298 \\
\hline OPE06 & 190,517 & 517 & 517 & & 517 & & 190 & 190 & 517 & $190,250^{*}$ & 190,517 & \\
\hline OPE13 & & & $344^{*}$ & & & & & & & & & $506^{*}$ \\
\hline OPE17 & 154 & & 154 & 154 & 154,420 & & 154 & 154 & 154,420 & 154,420 & 154 & 154 \\
\hline OPR05 & 100 & 100 & 85,100 & & 100 & 85,100 & 100 & 100 & 85,100 & 100 & & 85 \\
\hline OPR06 & & 344 & 344 & 344 & & & 344 & 220,344 & $220,450^{*}$ & 220 & 220 & 220 \\
\hline OPR07 & 270 & 270 & 270 & 270 & 270 & & & & $270,344 *$ & 270 & & 270 \\
\hline OPR10 & & & 506 & & & & & & & & 130 & $130,298 *, 506$ \\
\hline OPR11 & & $520^{*}$ & 250,344 & & 250 & 250 & 250,344 & 250,344 & 250,344 & 344 & & \\
\hline OPR16 & 1018 & 120 & $1100^{*}$ & 170 & & & 170 & 1018 & 120 & 170,1018 & 700 & $170,700,1018$ \\
\hline OPR17 & $201^{* 1)}$ & 134,850 & 850 & 134,850 & 134 & 134,850 & 134 & & 134 & & $506^{*}$ & \\
\hline ОРТ04 & 344 & 344 & 344 & & 344 & $154^{*}, 170^{*}$ & & & $190^{*}, 344$ & & $210^{*}$ & \\
\hline ОРТ09 & & 900 & & & & & & & $506^{*}, 900$ & & & \\
\hline OPT12 & 700 & 700 & 190,700 & 700 & 700 & 190 & & & 190 & & 190 & $298^{*}, 344^{*}, 700$ \\
\hline OPT14 & & & & & & 270 & 270 & 270 & & & & \\
\hline No. of bands & 12 & 18 & 20 & 9 & 14 & 12 & 15 & 13 & 24 & 15 & 14 & 19 \\
\hline
\end{tabular}

1) *; The number indicates the RAPD- specific marker for each type of MAL alone.

genome as an added chromosome. Therefore, the early bolting gene(s) in Brassicaceae seem to be diverse and to be expressed either dominantly or recessively in interspecific and intraspecific combinations.

Very little is known about the evolution and genetic analysis of the $\mathrm{C}_{3}-\mathrm{C}_{4}$ intermediate species in Brassicaceae including five species of Moricandia, Diplotaxis tenuifolia (L.) DC. and B. gravinae Ten.. In this study, the twelve types of MALs revealed the possibility of transferring useful agronomic traits from $M$. arvensis to $R$. sativus and provided suitable materials for analyzing the characteristics of the $\mathrm{C}_{3}-\mathrm{C}_{4}$ intermediate species. We are currently attempting to produce MALs between the other $\mathrm{C}_{3}-\mathrm{C}_{4}$ intermediate species of $D$. tenuifolia and $R$. sativus. Comparative studies of two MAL series of $R$. sativus - M. arvensis and R. sativus D. tenuifolia may provide more important information to understand the genetic system and evolution of the $\mathrm{C}_{3}-\mathrm{C}_{4}$ intermediate species in Brassicaceae.

\section{Literature Cited}

Apel,P., H.Bauwe and H.Ohle (1984) Hybrids between Brassica alboglabra and Moricandia arvensis and their photosynthetic properties. Biochem. Physiol. Pflanzen 179: 793-797.

Apel,P., S.Hillmer, M.Pfeffer and K.Muhle (1996) Carbon metabolism type of Diplotaxis tenuifolia (L.) DC. (Brassicaceae). Photosynthetica 32: 237-243.

Apel,P., C.Horstmann and M.Pfeffer (1997) The Moricandia syndrome in species of the Brassicaceae-evolutionary aspects. Photosynthetica 33: 205-215.

Bang,S.W., Y.Kaneko and Y.Matsuzawa (1996) Production of intergeneric hybrids between Raphanus and Moricandia. Plant Breed. 115: 385-390.

Chen,B.Y., V.Simonsen, C.Lanner-Herrera and W.K.Heneen (1992)
A Brassica campestris-albograbra addition line and its use for gene mapping, intergenomic gene transfer and generation of trisomics. Theor. Appl. Genet. 84: 592-599.

Chen,B.Y., R.B.Jørgensen, B.F.Cheng and W.K.Heneen (1997) Identification and chromosomal assignment of RAPD markers linked with a gene for seed colour in a Brassica campestrisalboglabra addition line. Hereditas 126: 133-138.

Chevre, A.M., F.Eber, P.This, P. Barret, X. Tanguy, H.Brun, M. Delseny and M.Renard (1996) Characterization of Brassica nigra chromosomes and of blackleg resistance in B. napus-B. nigra addition lines. Plant Breed. 115: 113-118.

Chevre,A.M., F.Eber, P.Barret, P.Dupuy and J.Brace (1997) Identification of the different Brassica nigra chromosomes from both sets of $B$. oleracea- $B$. nigra and $B$. napus- $B$. nigra addition lines with a special emphasis on chromosome transmission and self-incompatibility. Theor. Appl. Genet. 94: 603-611.

Jahier,J., A.M.Chevre, A.M.Tanguy and F.Eber (1989) Extraction of disomic addition lines of Brassica napus-B. nigra. Genome 32: 408-413.

Kagawa,A. (1971) Studies on the inheritance of flower inductive habit in Brassica crops. Bull. Fac. Agric. Gifu Univ. 31: 41-62.

Kaneko,Y., Y.Matsuzawa and M.Sarashima (1987) Breeding of the chromosome addition lines of radish with single kale chromosome. Jpn. J. Breed. 37: 438-452.

Kaneko,Y., H.Namai, Y.Matsuzawa and M.Sarashima (1991) Maintenance and stability of the chromosome addition lines of radish with single kale chromosome. Jpn. J. Breed. 41: 623-639.

Kaneko,Y., T.Natsuaki, S.W.Bang and Y.Matsuzawa (1996) Identification and evaluation of turnip mosaic virus (TuMV) resistance gene in kale monosomic addition lines of radish. Breed. Sci. 46: 117-124.

Kaneko,Y., S.W.Bang and Y.Matsuzawa (2000) Early-bolting trait and RAPD markers in the specific monosomic addition line of radish carrying the e-chromosome of Brassica oleracea. Plant Breed. 119: 137-140.

Kaneko,Y., H.Yano, S.W.Bang and Y.Matsuzawa (2001) Production 
and characterization of Raphanus sativus-Brassica rapa monosomic chromosome addition lines. Plant Breed. 120: 163-168.

Kirti,P.B., S.B.Narasimhulu, S.Prakash and V.L.Chopra (1992) Somatic hybridization between Brassica juncea and Moricandia arvensis by protoplast fusion. Plant Cell Rep. 11: 318-321.

Matsuzawa,Y., Y.Kaneko and S.W.Bang (1996) Prospects of the wide cross for genetics and plant breeding in Brassiceae. Bull. Coll. Agr. Utsunomiya Univ. 16: 5-10.

McGrath,J.M. and C.F.Quiros (1990) Generation of alien chromosome addition lines from synthetic Brassica napus: morphology, cytology, fertility, and chromosome transmission. Genome 33: 374-383.

Namai,H. (1987) Inducing cytogenetical alterations by means of interspecific and intergeneric hybridization in brassica crops. Gamma Field Symp. 26: 41-87.

Prakash, S., P.B.Kirti, S.R.Bhat, K.Gaikwad, V.D.Kumar and V.L. Chopra (1998) A Moricandia arvensis - based cytoplasmic male sterility and fertility restoration system in Brassica juncea. Theor. Appl. Genet. 97: 488-492.

Quiros,C.F., O.Ochoa, S.F.Kianian and D.Douches (1987) Analysis of the Brassica oleracea genome by the generation of $B$. campestris-oleracea chromosome addition lines: Characterization by isozymes and rDNA genes. Theor. Appl. Genet. 74: 758766.

Quiros,C.F., O.Ochoa and D.Douches (1988) Exploring the role of $\mathrm{x}=7$ species in Brassica evolution: hybridization with $B$. nigra and B. oleracea. J. Hered. 79: 351-358.

Razmjoo,K., K.Toriyama and R.Ishii (1996) Photosynthetic properties of hybrids between Diplotaxis muralis DC., a $\mathrm{C}_{3}$ species, and Moricandia arvensis (L.) DC., a $\mathrm{C}_{3}-\mathrm{C}_{4}$ intermediate species in
Brassicaceae. Genes Genet. Syst. 71: 189-192.

Shinohara,S. (1959) Genecological studies on the phasic development of flowering centering on the cruciferous crops, especially on the role of vernalization on ripening seeds. Tech. Bull. Shizuoka Pref. Agric. Exp. Stn. 6: 1-139.

Srinivasan,K., V.G.Malathi, P.B.Kirti, S.Prakash and V.L.Chopra (1998) Generation and characteristics of monosomic chromosome addition lines of Brassica campestris-B. oxyrrhina. Theor. Appl. Genet. 97: 976-981.

Takahata,Y. (1990) Production of intergeneric hybrids between a $\mathrm{C}_{3}-$ $\mathrm{C}_{4}$ intermediate species Moricandia arvensis and a $\mathrm{C}_{3}$ species Brassica oleracea, through ovary culture. Euphytica 46: 259264.

Takahata,Y. and T.Takeda (1990) Intergeneric (intersubtribe) hybridization between Moricandia arvensis and Brassica A and B genome species by ovary culture. Theor. Appl. Genet. 80: 38-42.

Takahata,Y., T.Takeda and N.Kaizuma (1993) Wide hybridization between Moricandia arvensis and Brassica amphidiploid species (B. napus and B. juncea). Euphytica 69: 155-160.

Toriyama,K., K.Hinata and T.Kameya (1987) Production of somatic hybrid plants, 'Brassicomoricandia', through protoplast fusion between Moricandia arvensis and Brassica oleracea. Plant Sci. 48: 123-128.

Yuasa,I. (1988) Some problems on the breeding of late-bolting. 3. Breeding of the late-bolting. (2) Radish. Breed. Tech. Symp. Seed Prod. Soc. Jpn. 37-44.

Zhu,J.S., D.Struss and G.Röbbelen (1993) Studies on resistance to Phoma lingam in Brassica napus-Brassica nigra addition lines. Plant Breed. 111: 192-197. 